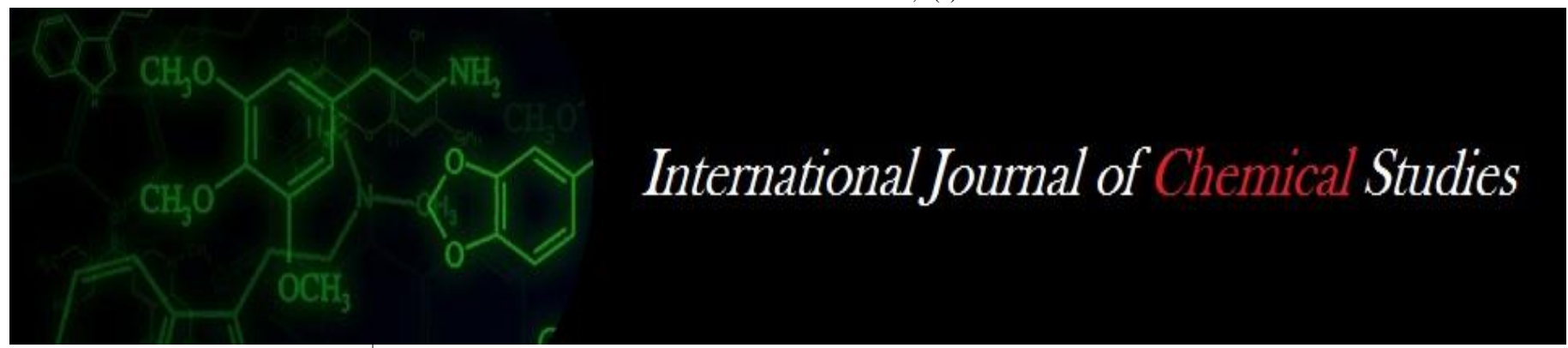

P-ISSN: 2349-8528

E-ISSN: 2321-4902

www.chemijournal.com

IJCS 2020; 8(5): 1576-1579

(C) 2020 IJCS

Received: 10-07-2020

Accepted: 12-08-2020

M Prashanthi Evangelin Southern Institute of Medical

Sciences, Guntur, Andhra

Pradesh, India

R Pauline Dorothy Kala

Southern Institute of Medical

Sciences, Guntur, Andhra

Pradesh, India

S Divya Bala

Southern Institute of Medical

Sciences, Guntur, Andhra

Pradesh, India

\section{Ayesha Ahmadi}

Southern Institute of Medical

Sciences, Guntur, Andhra

Pradesh, India

MD Hameeda Begum

Southern Institute of Medical

Sciences, Guntur, Andhra

Pradesh, India

\section{S Manohar Babu}

Southern Institute of Medical

Sciences, Guntur, Andhra

Pradesh, India
Corresponding Author:

M Prashanthi Evangelin Southern Institute of Medical

Sciences, Guntur, Andhra

Pradesh, India

\section{A review on human virus}

\section{Prashanthi Evangelin, R Pauline Dorothy Kala, S Divya Bala, Ayesha Ahmadi, MD Hameeda Begum and S Manohar Babu}

DOI: https://doi.org/10.22271/chemi.2020.v8.i5v.10521

\section{Abstract}

The Middle East respiratory syndrome coronavirus (MERS-CoV) was identified in human for the first time in the history. This is a zoonotic pathogen which was appeared first in Saudi Arabia and Jordan. According to WHO report, 858 deaths out of 27 countries were reported Between April 2012 and December 2019.The substrate at position P1 in glutamine is important for the protease of corona virus which is similar to that of 3 Cprotease in entero viruses. In the development of viral drugs, the best target is proteases having specificity and plays an important role in the processing of viral polyprotein. Based on the structure. Peptidomimetic ketoamides designed as potent, broad spectrum inhibitor of $3 \mathrm{c}$ proteases against corona viruses. The present review is focused on the symptoms, transmission, target and prevention of the virus.

Keywords: MERS-CoV, proteases, severe acute respiratory syndrome (SARS)

\section{Introduction}

Center East respiratory disorder (MERS) is a respiratory disorder caused because of infection spreader because of novice coronavirus (Middle East respiratory disorder coronavirus, or MERS-CoV) that was first recognized in Saudi Arabia in the year 2012.Coronaviruses are a major group of infections that can prompt illnesses with side effects of regular cold and Severe Acute Respiratory Syndrome (SARS).General MERS indications are fever, cough and insuffecient breath. Pneumonia is normal, yet not all that time. Gastrointestinal track side effects, including, diarrhea have likewise been recorded as information. Some research center positive instances of MERS-CoV disease are recorded as asymptomatic, in truth they don't have any clinical indications, yet they are sure for MERS-CoV contamination following a test in the lab. Agreeing WHO in the Year 2019 35\% of detailed patients with MERS-CoV disease have died (Favalli et al 2020) ${ }^{[5]}$ Even though the vast majority of human instances of MERS$\mathrm{CoV}$ diseases have been ascribed to human-to-human contaminations in the Health care sector, present research study proposes that dromedary camels are a significant reason for MERS$\mathrm{CoV}$ and a MERS infection of animal as source in human being. In any case, the specific job of dromedaries in transmission of the infection and the specific route(s) of transmission are obscure. The structure and replication of infection are portrayed in (Fig-1\&2).

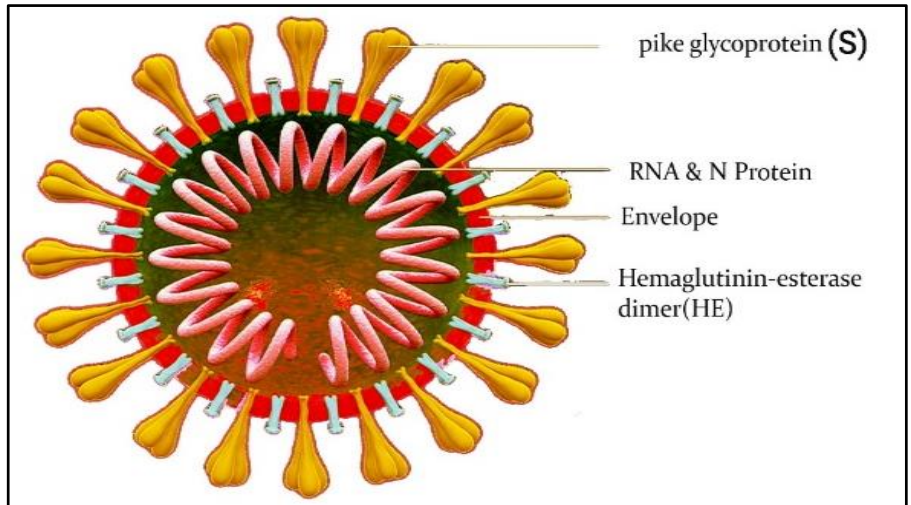

Fig 1: The Structure of Virus 


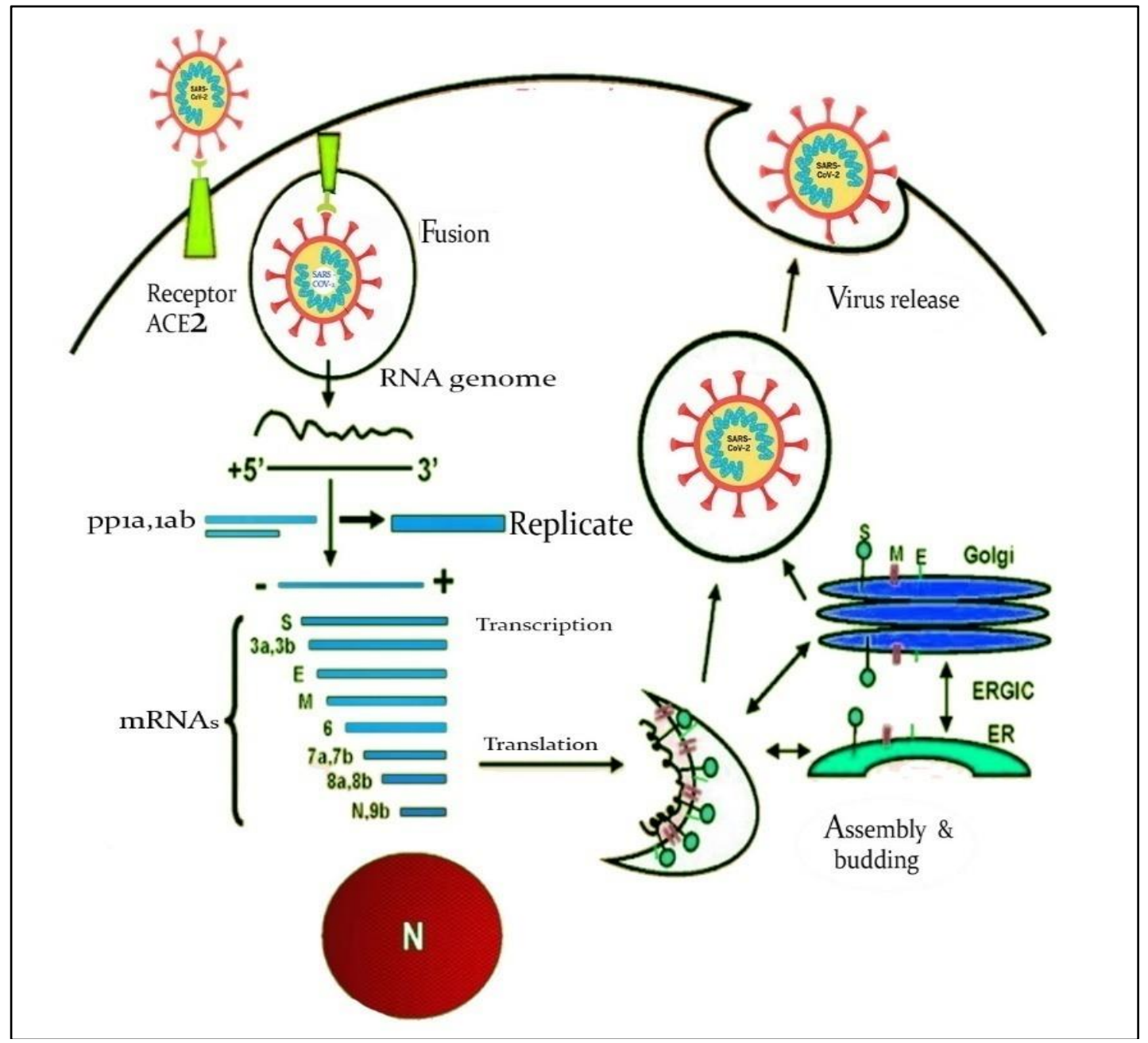

Fig 2: Replication of Virus

\section{Source of the virus}

This virus can be transmitted from animals and human beings as it is a zoonotic virus. The human beings are being transmitted due to dromedary camels which are infected previously. MERS-CoVis spreaded Mostly in Middle east countries like Africa, south asia (Alsalihi et al., 2019) ${ }^{[1]}$.

\section{Novel broad-spectrum antibiotic compound effective against corona viruses}

New compounds are identified by researchers which fight against new virus like corona, SARS-Cov) severe acute respiratory syndrome, Middle-East respiratory disease virus (MERS-CoV). The main target is protease identified by scientist for viral replication. In this process an effort on combating the corona virus by broad-spectrum antivirals by researchers was outstanding. It was investigated by scientist that by selecting $3 \mathrm{C}$ protease as target in viral replication, which is a similar protein like enteroviruses causing many diseases like common cold, mouth, foot infections. Structures of proteases were examined by $\mathrm{x}$ ray crystallography by researchers and then designed series of $\alpha$-ketoamide compounds (fig-3). It is tested in human by blocking the enzyme active site or binding it (Linlin Zhang et al., 2020) ${ }^{[12]}$ Researchers founded that alongside the likenesses between SARS-CoV and SARS-CoV-2, there is hereditary variety between the two and it isn't clear if epitopes that investigate an immuno reaction against SARS-CoV will be successful against SARS-CoV-2. They had found that only 20 percent of the SARS-CoV epitopes map like SARS-CoV-2 and accepted as promising compounds."

\section{Target for Corona}

The substrate at position P1 in glutamine is important for the protease of corona virus which is similar to that of 3Cprotease in the entero viruses. In the development of viral drugs the best target is proteases having specificity and plays an important role in the processing of viral polyprotein. Based on the structure Peptidomimetic ketoamides designed as potent, broad spectrum inhibitor of $3 \mathrm{c}$ proteases against corona viruses.

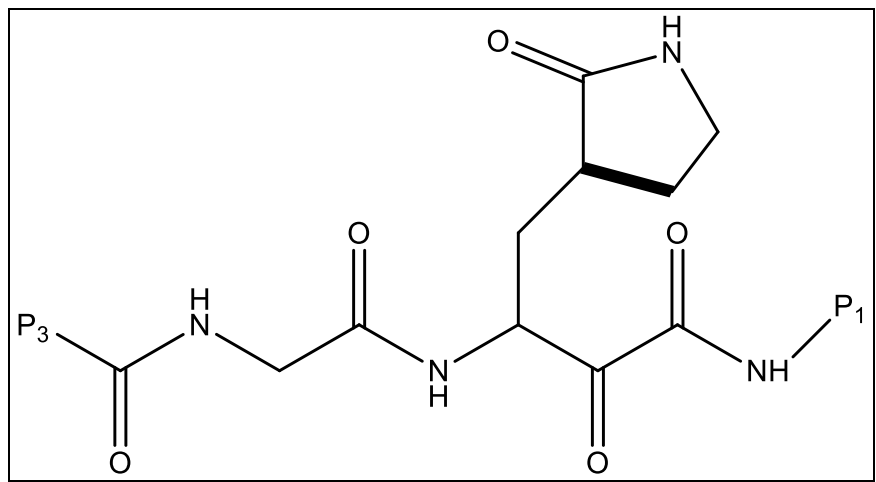

Fig 3: $\alpha$-ketoamide compound

Since the year 2003 there has been an outbreak of acute respiratory syndrome (SARS) and now 17 yrs is passing away but still there is no perfect cure for (SARS-CoV) (Hilgenfeld et al., 2013) [7]. Pateint suffering from SARS and its consequences is prevailing on other side development of antiviral drugs and its commercial in viability ended in rapid 
increase but not appeared in 2004. Due to this Middle East respiratory syndrome coronavirus (MERS-CoV) which is the native of SARS-CoV resulted in 2012.MERS is perceived by respiratory illness, same as SARS, alongside, once in a while causes renal failure (Zaki et al., 2012). At the same time number of enrolled MERS cases is less (2494 as of November 30, 2019), the pios MERS-CoV is comparativley more dangerous than that introduced by SARS-CoV. The fatality rate is high(about $35 \%$, contrasted with $10 \%$ for SARS) and truly MERS cases are as yet reestablishing seven years after the revelation of the infection, while the SARS flare-up was generally contained between a half year. The capacity for human-to-human transmission of MERS-CoV has been illustrated positively in the year 2015 eruption in South Korea, where 186 cases can be detected back to a first contaminated tourist coming back from the Middle East (Eckerle et al., 2013) ${ }^{[4]}$. SARS-like coronaviruses are as yet existing in bats in China from where they may numerous over into the human populace (Butler et al., 2015) ${ }^{[3]}$ (Ge et al., 2013) ${ }^{[6]}$ (Menachery et al., 2015) ${ }^{[9]}$. This is most likely what caused eruption of atypical pneumonia in Wuhan, which is associated with a fish and many seafood, animal outlets. The RNA genome (GenBank promotion code: MN908947.3) of the new beta coronavirus includes around $82 \%$ similar from that of SARS-CoV (Yang et al., $2016^{[10]}$ (Hu et al., 2017) ${ }^{[8]}$

\section{Symptoms}

The symptoms of MERS-CoV infection varies from asymptomatic or mild respiratory symptoms to SAR disease and sometimes leads to death. The most common symptoms of MERS-CoV disease is fever, cough and shortness of breath. Pneumonia is a commonly seen, but does not exist all time. Gastrointestinal tack symptoms, including diarrhea, have also been reported. The patient suffers from breathing problem due to insufficient flow of air and in such cases ventilators are strongly recommended. This virus is infected to the person having less immunity power with more age group ie above 60yrs and in infant with less than 5yrs. The patient with renal disorders and tumors, diabetes, chronic lung disorders are having the risk of getting the infection.
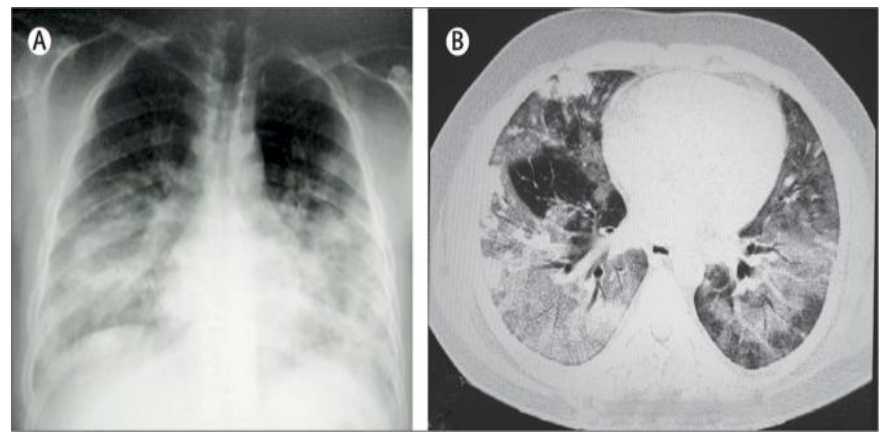

As Per Data Mostly 35\% of patients with MERS have passed on, however this might be an overestimate of the genuine death rate, as some mild cases of MERS might be missed in the survey and until more is thought about the infection, the fatality rate of cases is numbered among the research lab affirmed cases (Zumla et al., 2015) ${ }^{[13]}$.

\section{Scientists suggest T-cell epitopes that could be targeted by} Coronavirus vaccines

Different targets and different therapies search for various types of coronaviruses by researchers. Scientist from the Hong Kong University of Science and Technology (HKUST) investigated the B-cell and T-cell spike and nucleocapsid protein epitopes that result in response to SARS-CoV-1, which leads to disease, to find biomarkers that could be injected into vaccines to trigger an immune response to SARS-CoV-2. According to the researchers, no mutations have been seen in the SARS-CoV-2 epitopes they have enlightened, so immune targeting of these may give protection against COVID-19. The research team advised their work, published in the Viruses, can now be upheld on by drug development industries to teach their R\&D of a COVID19 vaccine (Ahmed et al., 2020) ${ }^{[2]}$

\section{Prevention and treatment}

The best way to avoid the infection is to maintain selfhygiene, mostly when visiting market places and farms and other public places. As of, there are no vaccines and medicaments available currently. Researchers are sorting out the new methods in developing the novel drug (Favalli et al., 2020) ${ }^{[5]}$.

\section{Conclusion}

MERS-CoV is widely distributed in the areas of middle east countries, causing sporadic human disease and reminded in WHO Blueprint 2020 list of priorities. To avoid the further spread and to reduce the deaths all countries should invest on research activities and vaccine invention.

\section{References}

1. Alsalihi SF, Jawad AA, Al-Rodhan MA. September. Molecular Study and Phylogenetic Analysis of Middle East Respiratory Syndrome Corona Virus (MERSCoV) in Camel and Human. In Journal of Physics: Conference Series IOP Publishing. 2019; 1294(6):062-097.

2. Ahmed SF, Quadeer AA, McKay MR. Preliminary identification of potential vaccine targets for the COVID19 coronavirus (SARS-CoV-2) based1. on SARS-CoV immunological studies. Viruses, 2020; 12(3):254.

3. Butler D. South Korean MERS outbreak spotlights lack of research. Nature. 2015; 522:139-140.

4. Eckerle I, Muller MA, Kallies S, Gotthardt DN, Drosten C. In-vitro renal epithelial cell infection reveals a viral kidney tropism as a potential mechanism for acute renal failure during Middle East Respiratory Syndrome (MERS) Coronavirus infection. Virol. J. 2013; 10:359.

5. Favalli EG, Ingegnoli F, De Lucia O, Cincinelli G, Cimaz R, Caporali R. COVID-19 infection and rheumatoid arthritis: Faraway, so close!. Autoimmunity Reviews. 2020, 102523.

6. Ge XY, Li JL, Yang XL, Chmura AA, Zhu G, Epstein $\mathrm{JH}$ et al. Isolation and characterization of a bat SARSlike coronavirus that uses the ACE2 receptor. Nature. 2013; 503:535-538.

7. Hilgenfeld R, Peiris M. From SARS to MERS: 10 years of research on highly pathogenic human coronaviruses. Antiviral Res. 2013; 100:286-295.

8. Hu B, Zeng LP, Yang XL, Ge XY, Zhang W, Li B, et al. Discovery of a rich gene pool of bat SARS-related coronaviruses provides new insights into the origin of SARS coronavirus. PLoS Pathog, 2017.

9. Menachery VD, Yount BL, Jr. Debbink, K, Agnihothram, S, Gralinski LE, Plante JA et al. A SARS-like cluster of circulating bat coronaviruses shows potential for human emergence. Nat. Med. 2015; 21:1508-1513.

10. Yang XL, Hu B, Wang B, Wang MN, Zhang Q, Zhang $\mathrm{W}$ et al. Isolation and characterization of a novel bat 
coronavirus closely related to the direct progenitor of severe acute respiratory syndrome coronavirus. J Virol. 2016; 90:3253-3256.

11. Zaki AM, van Boheemen S, Bestebroer TM, Osterhaus $\mathrm{AD}$, Fouchier RA. Isolation of a novel coronavirus from a man with pneumonia in Saudi Arabia. N. Engl. J Med. 2012, 367:1814-182.

12. Zhang L, Lin D, Sun X, Curth U, Drosten C, Sauerhering L et al. Crystal structure of SARS-CoV-2 main protease provides a basis for design of improved $\alpha$-ketoamide inhibitors. Science, 2020.

13. Zumla AHui DS Perlman SMiddle East respiratory syndrome. Lancet. 2015; 386:995-1007. 